\title{
LITURATERRA [Resenha: 2018, 4]
}

\author{
O Jardim Secreto
}

DOI: 10.15175/1984-2503-201810309

\section{Gisálio Cerqueira Filho*}

\section{LITURATERRA [Resenha: 2018,4]}

As resenhas, passagens literárias e passagens estéticas em Passagens: Revista Internacional de História Política e Cultura Jurídica são editadas na seção cujo título apropriado é LITURATERRA. Trata-se de um neologismo criado por Jacques Lacan ${ }^{1}$, para dar conta dos múltiplos efeitos inscritos nos deslizamentos semânticos e jogos de palavras tomando como ponto de partida o equívoco de James Joyce quando desliza de letter (letra/carta) para litter (lixo), para não dizer das referências a Lino, litura, liturarios para falar de história política, do Papa que sucedeu ao primeiro (Pedro), da cultura da terra, de estética, direito, literatura, inclusive jurídicas - canônicas e não canônicas - ainda e quando tais expressões se pretendam distantes daquelas religiosas, dogmáticas, fundamentalistas, para significar apenas dominantes ou hegemônicas.

\footnotetext{
* Full Professor at Fluminense Federal University, Niterói, Rio de Janeiro, Brasil and member of RCSL (Research Committee on Sociology of Law/International Sociological Association). E-mail: gisalio@superig.com.br. Orcid ID: https://orcid.org/0000-0001-5047-4376

${ }^{1}$ Lacan, Jacques. Outros Escritos. Tradução Vera Ribeiro; versão final Angelina Harari e Marcus André Vieira; preparação de texto André Telles, Rio de Janeiro: Zahar, 2003, p. 11-25. [Lacan, Jacques (2001). Autres Écrits, Paris: Éditions de Seuil.
}

Recebido em 06 de agosto e aprovado para publicação em 27 de agosto de 2018. 


\section{Passagens. Revista Internacional de História Política e Cultura Jurídica}

Rio de Janeiro: vol. 10, n⿳3, setembro-dezembro, 2018, p. 502-507.

\section{LITURATERRA [Reseña: 2018,4]}

Las reseñas, incursiones literarias y pasajes estéticos en Passagens: Revista Internacional de Historia Política y Cultura Jurídica son publicadas en una sección apropiadamente titulada LITURATERRA. Se trata de un neologismo creado por Jacques Lacan para dar cuenta de los múltiples efectos introducidos en los giros semánticos y juegos de palabras que toman como punto de partida el equívoco de James Joyce cuando pasa de letter (letra/carta) a litter (basura), sin olvidar las referencias a Lino, litura, liturarios para hablar de historia política, del Papa que sucedió al primero (Pedro), de la cultura de la terre (tierra), de estética, de derecho, de literatura, hasta jurídica - canónica y no canónica. Se da prioridad a las contribuciones distantes de expresiones religiosas, dogmáticas o fundamentalistas, para no decir dominantes o hegemónicas.

\section{LITURATERRA [Review: 2018,4]}

The reviews, literary passages and esthetic passages in Passagens: International Journal of Political History and Legal Culture are published in a section entitled LITURATERRA [Lituraterre]. This neologism was created by Jacques Lacan, to refer to the multiple effects present in semantic slips and word plays, taking James Joyce's slip in using letter for litter as a starting point, not to mention the references to Lino, litura and liturarius in referring to political history, to the Pope to have succeeded the first (Peter); the culture of the terra [earth], aesthetics, law, literature, as well as the legal references - both canonical and non-canonical - when such expressions are distanced from those which are religious, dogmatic or fundamentalist, merely meaning 'dominant' or 'hegemonic'.

\section{LITURATERRA [Compte rendu: 2018,4]}

Les comptes rendus, les incursions littéraires et les considérations esthétiques Passagens. Revue Internationale d'Histoire Politique et de Culture Juridique sont publiés dans une section au titre on ne peut plus approprié, LITURATERRA. II s'agit d'un néologisme proposé par Jacques Lacan pour rendre compte des multiples effets inscrits dans les glissements sémantiques et les jeux de mots, avec comme point de départ l'équivoque de James Joyce lorsqu'il passe de letter (lettre) à litter (détritus), sans oublier les références à Lino, litura et liturarius pour parler d'histoire politique, du Pape qui a succédé à Pierre, de la culture de la terre, d'esthétique, de droit, de littérature, y compris juridique - canonique et non canonique. Nous privilégierons les contributions distantes des expressions religieuses, dogmatiques ou fondamentalistes, pour ne pas dire dominantes ou hégémoniques.

\section{文字国 [图书梗概:2018,4]}

Passagens 电子杂志在“文字国”专栏刊登一些图书梗概和文学随笔。PASSAGENS一 国际政治历史和法学文 化电子杂志开通了“文字国”专栏。“文字国”是法国哲学家雅克，拉孔的发明，包涵了语义扩散，文字游戏，从 爱尔兰作家詹姆斯 . 乔伊斯 的笔误开始, 乔伊斯把letter (字母/信函)写成了litter (垃圾), 拉孔举例了其他文字游 戏和笔误, lino, litura, liturarios, 谈到了政治历史, 关于第二个教皇(第一个教皇是耶稣的大弟子彼得), 关于土 地的文化 [Cultura一词多义, 可翻译成文化, 也可翻译成农作物], 拉孔联系到美学, 法学,文学, 包括司法学一 古典法和非古典法, 然后从经典文本延伸到宗教, 教条, 原教旨主义, 意思是指那些占主导地位的或霸权地位的 事物。 


\section{O Jardim Secreto}

\section{Gisálio Cerqueira Filho}

CHESTERTON, Gilbert Keith. O Jardim Secreto - The Secret Garden. Tradução de Gil Reyes. São Paulo: Folha de S. Paulo, 2018. Coleção Folha Inglês com Clássicos da Literatura, v. 15. Edição bilíngue.

Gilbert Keith Chesterton (29/05/1874 - 14/06/ 1936), (re)conhecido como tomista de fôlego foi não apenas um escritor inglês, mas polemista do paradoxo, implicado definitivamente em incorporar a intuição e a imaginação no paradigma racionalista que reporta a Santo Tomás de Aquino. Dedicou-se à literatura, poesia e à crítica de arte. Foi dramaturgo, biógrafo, teólogo, jornalista. Referindo-se a si próprio como adepto da ortodoxia cristã, identificou-se primeiramente com o anglicanismo, e mais tarde, a partir de 1922, converteu-se definitivamente ao catolicismo. G. K. Chesterton casou com Frances Blog em 1902, tendo vivido com ela toda a vida.

Muitos o consideram uma espécie de sucessor de John Henry Newman (21/02/180111/08/1890), também anglicano, mas devotado à vida sacerdotal e que se converteu ao catolicismo em 1845 com grande repercussão na opinião pública de então. Em Birminghan, dirigiu um oratório de São Felipe Néri, tendo pertencido à Ordem dos Oratorianos e chegou a ser reitor na Universidade Católica da Irlanda (1854).

Chesterton utilizava-se dos meios de comunicação, particularmente do rádio, para difundir o catolicismo e, em particular o tomismo; muitas vezes com foco na doutrina social da Igreja ou no debate "laicização X clericalismo" fazendo uso particular de provérbios, ditos populares da fácil compreensão dos ouvintes ou leitores, quase sempre fascinados com suas comparações alegóricas, chistes, metáfora e metonímias destinadas a produzir efeitos precisos. 
No universo da fiç̧ão foi responsável pela criação do personagem sacerdotedetetive Pe. Brown, com erudita, mas compreensível, apologética.

O papel desempenhado pelo campo católico-anglicano, especialmente pelo Reverendo Newman e por Chesterton, repercutiu na chamada reconversão de Joaquim Nabuco, no apagar das luzes do império no Brasil e pouco mais tarde de Gilberto Freyre, quando vira as costas para Baylor University, nos EUA, de confissão batista. Na ocasião, travou contato com o pensamento de Chesterton na sua viagem à Inglaterra. Tal percurso ainda aguarda apuração atenta, reflexão e interpretações aprofundadas. E talvez possamos dizer o mesmo para as conversões ao catolicismo de Jackson de Figueiredo (1918) ou Alceu Amoroso Lima (1928). Incluímos neste rol também Rui Barbosa e Gustavo Corção. Pois que estava em curso a chamada terceira escolástica, na qual o papa Leão XIII (02/03/1810 - 20/08/1903) teve papel primordial. Tornado Papa a partir de 20 de fevereiro de 1878, foi o responsável pela encíclica Rerum Novarum, publicada em 15 de maio de 1891 e pelo chamamento da Igreja à presença no cotidiano mundano.

A continuidade da terceira escolástica deu-se durante o pontificado de Pio X (19031914). Marcos a serem destacados são o "juramento antimodernista" e o "Código Canônico" (Codex luris Canonici), outorgado durante o pontificado de Bento XV (1914-1922). Enquanto a primeira medida visava contrapor-se especialmente ao relativismo, a segunda ratificava a doutrina da Igreja em oposição às modernas codificações civis que emergiam na Europa. O Código criou a Congregazione per L'Educazione Cattolica, que determinou o ensino da filosofia e da teologia segundo o método e a doutrina de Tomás de Aquino nos seminários e nas escolas católicas.

O Jardim Secreto data de 1910 e se inscreve na valorização do tomismo, de quem o autor G. K. Chesterton é grande defensor. Assim, a obra Ortodoxia (Londres, 1908) é um precioso exercício para defender a visão filosófica da fé perante o racionalismo. Com o famoso sense of humour inglês, Chesterton subjetiva-se e implica-se no próprio processo de sua conversão do agnosticismo para o cristianismo, mostrando a coerência e a beleza da doutrina cristã no embate contra as filosofias modernistas.

Foi o psicanalista Jacques Lacan que definiu o symptôme (sintoma) da nossa época com as ideias de São Tomás (portanto do tomismo) pela homofonia que acarretava a expressão original em francês. J. Lacan constituiu-se, e ao seu pensamento, num lugar epistemológico que dialoga criticamente com o tomismo. Já Sigmund Freud, que tem um 
referencial judaico, tem também certa fascinação pelo tomismo como, talvez, um dos avatares das neuroses e psicoses. ${ }^{2}$

No caso presente, o conto que temos é a explicitação de algumas teses correntes do tomismo de Chesterton encarnadas no protagonismo do personagem detetive, $\mathrm{Pe}$. Brown. Um sacerdote detetive sistemático e metódico... A edição bilíngue é o volume 15 da coleção "Folha Inglês com Clássicos da Literatura" e patrocinada pelo jornal Folha de $S$. Paulo. Constitui-se em valioso exemplar também para aqueles que desejam acompanhar na língua original as diatribes do pe. Brown.

Ele recorre ao método indiciário na busca dos sinais, pistas, indícios, sintomas, que possam levar ao(s) assassino(s), mas sobretudo permita colher as tiradas de sabedoria do autor, inclusive aquelas com forte acento ideológico contra a laicização da vida (para ele e outros tantos intelectuais, o momento de virada foi a revolução francesa de 1789), cujos efeitos deletérios continuaram sendo produzidos, seja contra o clericalismo, a religião e até mesmo a fé. Pelo menos uma anedota ganhou o mundo acerca do visual físico de Chesterton. Sendo um homem gordo e grande; embora fosse alto, possuía uma barriga avantajada para os seus 1,93 m de altura e $130 \mathrm{~kg}$ de peso. Assim, em certa ocasião e pelo tempo da Primeira Guerra Mundial, uma senhora indagou-lhe em Londres "por que o senhor não está lá na frente de batalha?" E ele teria respondido. "Se você me der a volta completa, você verá que eu estou”. De fato, o homem era incansável, na sua luta intelectual...

\section{Sintoma e Sinthomen}

Entretanto, e este é o ponto chave para Lacan: e quando, embora devidamente interpretado, o sintoma, não se desfaz? Nos últimos anos de seu ensino, o sintoma deixa de ser uma mensagem meramente cifrada, e passa a ser concebido como também e muito especialmente, uma maneira do sujeito organizar o seu gozo (jouissance). Certamente esta é a maior razão para o sujeito não renunciar, assim sem mais, ao seu sintoma. Lacan diz então que nesse caso o sintoma converte-se em sinthomen, neologismo para falar do "pedaço da fantasia na qual o gozo é reeditado na demanda constante do pedaço do real

2 Imbricam-se aqui a obsessão pela perfeição, o perfeccionismo, a idealização, bem como os conceitos psicanalíticos "Eu ideal" e "Ideal do Eu" (Cf. BORRMANN, 2009). . 
contingente em que o desejo fica preso" (CERQUEIRA FILHO; NEDER, 1997 especialmente cap. 6). ${ }^{\text {a }}$

Para Lacan este neologismo se presta a diversas associações: a síntese entre sintoma e fantasia, o homem artificial, o santo homem, Santo Tomás, o homem santo, o homem sintético idealizado, enfim o super-homem... O sintoma concebido como sinthomen é, literalmente, nossa única substância, o único esteio positivo do nosso ser, o único ponto que dá consistência ao sujeito. Quando o sintoma nesta concepção radical se desfaz, isso significa a ato de se deixar levar pela pulsão de morte até a destruição total do universo simbólico.

\section{Um conto peculiar numa coleção peculiar}

O conto em questão compõe, como ressaltamos, a coleção "Folha Inglês com Clássicos da Literatura", publicado pelo jornal a Folha de S. Paulo, mas num esforço didático e pedagógico admirável. Além de conter a versão em português e inglês página a página e lado a lado, o volume vem com um código pessoal para acesso tanto ao audiobook da história em inglês, que visa o aperfeiçoamento da compreensão oral, quanto ao e-book da versão original que pode ser acessado através de download devidamente ativado.

Todavia o que gostaríamos de ressaltar é precisamente o aspecto tomista do pensamento de Chesterton, mesmo quando se trata do Padre Brown detetive. Chesterton teve a capacidade e a sensibilidade para dizer Presente! onde quer que o sintoma do tomismo se apresente.

\section{Referências}

BORRMANN, Ricardo. Tal mercado, tal príncipe: o paradigma da perfeição na economia política burguesa. 2009. Dissertação (Mestrado)-Programa de Pós-Graduação em Ciência Política, Universidade Federal Fluminense, Niterói, 2009. ${ }^{\text {a }}$

CERQUEIRA FILHO, Gisálio; NEDER, Gizlene. Emoção e política: (a)ventura e imaginação sociológica para o século XXI. Porto Alegre: SAFE, 1997. ${ }^{a}$ 